\title{
Patients and Populations: Necessary Links between the Two Approaches to Pediatric Research
}

\author{
BARBARA STARFIELD ${ }^{(16)}$ \\ The Johns Hopkins University School of Hygiene and Public Health, Division of Health Care Organization. \\ Baltimore, Maryland, USA \\ Symposium: "Frontiers of Pediatric Research and the Shaping of Public Policy"
}

The opportunity to stress the importance of linkages between community-based, or population-based, research and clinical and basic research is most welcome. I hope to convey that the two approaches are interrelated and that their separateness (like two sides of a coin) is a corollary of the fact that one loses meaning without the other.

There has, of course, always been tension between mass and individual approaches to the understanding of disease causation and management. The end of the previous century must have witnessed debates as exciting as those we are experiencingbetween the social medicine propounded so vigorously by Virchow and the individualistic approaches resulting from Pasteur's discoveries. Within the 20 th centrury, there have been periods when population-based approaches have been most effective and other periods when the impact has derived primarily from individual medical care. Hindsight has shown that the two approaches have been complementary, with advances in one producing sufficient change in the substrate of diseases to create conditions under which the other can flourish. The sanitary movement of the late 1800 's and early 1900's made it feasible to attack infectious disease at an individual level. Now medical technology has given us strategies of management that cannot be applied because of gaps in knowledge about problems as they exist in the community.

The types of advances made in research are, in the last analysis, dependent on what problems are chosen by researchers. Reflect a moment on how you chose the area that occupies most of your research time. Although most would prefer to think that their research area is chosen after careful deliberation concerning the potential importance of the issue and its intellectual challenge, potential researchers are extremely unlikely to choose an area to which they have had no exposure. Therefore, the breadth of potential research topics confronted in medical schools and postgraduate training is critical in determining the kinds of research that investigators pursue. Unless the current research focus is broadened, there will continue to be inadequate investigation of concerns related to children.

A maximum of 10 to $11 \%$ of children in this country, regardless of age, relates to a place as the regular source of care (7). Only a portion of these $10 \%$, actually only $6 \%$ of children, relates to a hospital clinic as the regular source of care so that even fewer than this relate to a teaching clinic. Specialty clinics are an even more highly selected group. This was dramatically illustrated by Kerr White (14) who showed that only one in a thousand adults in the population is referred to a medical center in a month. No comparable data exist for children, but there is no reason to believe that the findings would be any different.

The first point, then, is that knowledge about the distribution of health problems in the population (all health problems, the whole population of children) cannot be derived from experiences in medical centers. Nor do textbooks or lectures help much. Seldom do they contain information about the incidence or prevalence of most of the conditions they describe, so that students have no basis for judging the relative importance or impact of problems they see. A colleague of mine who participated in giving a course in the pathophysiology of disease provided a vivid example of this. In this course, one session was devoted to diseases producing hyperglycemia; lectures of equal time were devoted to diabetes mellitus and Cushing's disease. After the lectures, my colleague asked students if they had any idea of the relative frequency of the two conditions. Most students replied that they probably were of equal frequency. On the basis of what they study, students are misled with incomplete information about things that will comprise most of their practice, and those who enter research may select topics without adequate knowledge about the scope of possibilities for research.

Nor will experience with patients in medical centers provide knowledge about the way diseases present, the second reason for linking the two types of research. Most researchers, based as they are at medical centers, are at the tail end of the diagnostic chain and see diseases relatively late in their evolution. The full panoply of symptoms and signs as they exist in the community are unrepresented in the patients seen in medical centers. A recent article in "Pediatrics" (4) vividly demonstrated this by showing that pediatricians asked to indicate the usual presenting findings for several genetic metabolic diseases cited the pathognomic sign, which is seldom the problem for which medical attention is sought. As long as physicians are not taught the common conditions with which these disorders present, they will not search for the characteristic finding.

There isn't much opportunity, particularly in medical centers, to see the results of medical care interventions, either, the third reason to augment basic and clinical research with communitybased research. A typical child receives care from many different places (5). Each place deals with only a portion of the child's health problems. Moreover, physicians vastly overestimate the extent to which they are central in the patient's health care. With the exception of physicians in public clinics, physicians in Washington, D. C. (1) claimed that most patients were regular users of care at their facility; in three of the facilities the doctors thought all patients were regular patients. Yet, in some facilities more than two of five visits that children made were to other sources of care than the one identified as the regular source. Physicians are frequently unaware of the fact that patients are receiving care elsewhere even while under their own care (12). Table 1 shows that in three very different facilities, one in a teaching hospital, one in an urban prepaid group, and one in a suburban prepaid group, a large proportion of child patients made a visit elsewhere during a period in which they were under care of a particular physician for a particular problem. The primary care practitioner scheduled a visit to another clinic or physician for one in nine 
Table 1. Continuity of care; percentage of pediatric patients with intervening visits 1

\begin{tabular}{lccc}
\hline & $\begin{array}{c}\text { Suburban } \\
\text { group (\%) }\end{array}$ & $\begin{array}{c}\text { Urban } \\
\text { group (\%) }\end{array}$ & $\begin{array}{c}\text { University } \\
\text { hospital (\%) }\end{array}$ \\
\hline $\begin{array}{l}\text { Visit scheduled by } \\
\begin{array}{c}\text { practitioner } \\
\text { Visit unanticipated by } \\
\text { practitioner }\end{array}\end{array}$ & 11 & 12 & 12 \\
\hline
\end{tabular}

${ }^{1}$ Source: adapted from Ref. 12.

children sometime during the interval between two regular followup visits. In addition, at least one in 10 children made an unanticipated visit elsewhere during this intervening period.

The physicians who were caring for the patient sometimes followed up on the occurrence of the visits they themselves scheduled, but they infrequently followed up on visits the patient made on his own (Table 2). At most, only about a quarter of these visits were recognized. Moreover, the content of these visits, the diagnoses and therapies, was rarely integrated into the care given these patients, even though in some proportion of cases it must have had a bearing on the management of the problem being followed. As Table 3 shows, the problems noted in these intervening visits were recognized much less readily in every one of the facilities than the problems for which the patient was being followed. It is clear that the physicians seeing children do not know the full burden of the children's illnesses. Most children are seen sporadically or not at all, whether their care is provided in offices, outpatient departments, or specialty clinics. And even if some children are seen regularly, either in general or specialty clinic, it is for only a subset of their problems.

Because care is so fragmented, practitioners often have little idea of what patients understand about their diagnosis and therapy. Studies have shown that patients generally remember only about one-half of what doctors tell them, and this is not only for clinic patients but for patients of all types (6). As a result, a large number of patients don't even know the problems for which they are being treated or followed. The data in Table 4 are from a study in two different health maintenance organizations. Just after a visit, both the patients and practitioners were asked to indicate what problems needed follow-up the next time the patient returned. Of all the children's problems, $1 / 5$ were mentioned by the practitioner only, and $1 / 5$ were mentioned by the patient only. The patients and their practitioners agreed on what the problems were only about $60 \%$ of the time. The huge literature on compliance (8) documents again and again that the treatments and advice prescribed are often not adhered to, and although the earlier studies sought, explanations for this in particular patient characteristics, more recent studies show the importance of factors such as simple lack of knowledge of the patient about the nature of the therapy or its purpose and factors such as excessively complex and unreasonable regimens.

Inadequate knowledge about the constellation of patients' problems and about the extensive amount of care provided elsewhere makes it very difficult for physicians to learn of successes, or more seriously, of failures in management. Even researchers have a problem assessing the results of their diagnostic and therapeutic endeavors. Perhaps that explains in part why the majority of studies reported in the literature are scientifically unsound $(2,9$, 15). In a system where patients who do not get relief or who get better may well go elsewhere for their care, this loss of information about the results of therapy is a serious disservice to patients, to practitioners, and to the accumulation of scientific knowledge. This is the third reason for expanding research to include population-based investigations.

The fourth reason for linkages between the types of research is that the organization of teaching facilities constrains the types of problems that physicians recognize. Physicians in busy outpatient facilities have neither the time nor the motivation to deal with certain types of problems, problems that are an important aspect of child health in the community. Figure 1 shows that practitioners in pediatric teaching facilities make a diagnosis of a psychosocial problem less often than do practitioners in other types of facilities that care for children. These data come from facilities in six different cities (10), but the differences among them are not due to differences in prevalence of problems in their populations. As Figure 2 shows, the facilities hardly vary at all in the extent to which psychosomatic problems-asthma, headache, abdominal pain-are recognized in the children. The differences are limited to recognition of psychosocial problems only.

The fifth reason for increased links between basic, clinical, and population-based research concerns the inadequate knowledge

Table 2. Percentage of visits that were followed up by practitioners caring for children ${ }^{1}$

\begin{tabular}{lccc}
\hline & $\begin{array}{c}\text { Suburban } \\
\text { group (\%) }\end{array}$ & $\begin{array}{c}\text { Urban } \\
\text { group (\%) }\end{array}$ & $\begin{array}{c}\text { University } \\
\text { hospital (\%) }\end{array}$ \\
\hline Visit scheduled & 52 & 33 & 64 \\
Visit not anticipated & 17 & 21 & 27 \\
\hline
\end{tabular}

${ }^{1}$ Source: adapted from Ref. 12.

Table 3. Percentage of childrens' problems followed up by practitioner

\begin{tabular}{lccc}
\hline & $\begin{array}{c}\text { Suburban } \\
\text { group (\%) }\end{array}$ & $\begin{array}{c}\text { Urban } \\
\text { group (\%) }\end{array}$ & $\begin{array}{c}\text { University } \\
\text { hospital (\%) }\end{array}$ \\
\hline $\begin{array}{l}\text { Problems under practi- } \\
\text { tioner's care }\end{array}$ & 68 & 72 & 80 \\
$\begin{array}{l}\text { Problems in interven- } \\
\text { ing visits }\end{array}$ & 20 & 50 & 73 \\
\hline
\end{tabular}

'Source: adapted from Ref. 12.

Table 4. Percentage of children's problems said to need follow-up

\begin{tabular}{lrc}
\hline & No. & $\%$ \\
\hline Problem mentioned by practitioner only & 30 & 18.4 \\
Problem mentioned by patient only & 33 & 20.4 \\
Problem mentioned by both practitioner and pa- & 100 & 61.3 \\
tient & &
\end{tabular}

' Source: adapted from Ref. 12. Percent of Visits with Psychosocial Diagnoses
Age-Standardized. 1977

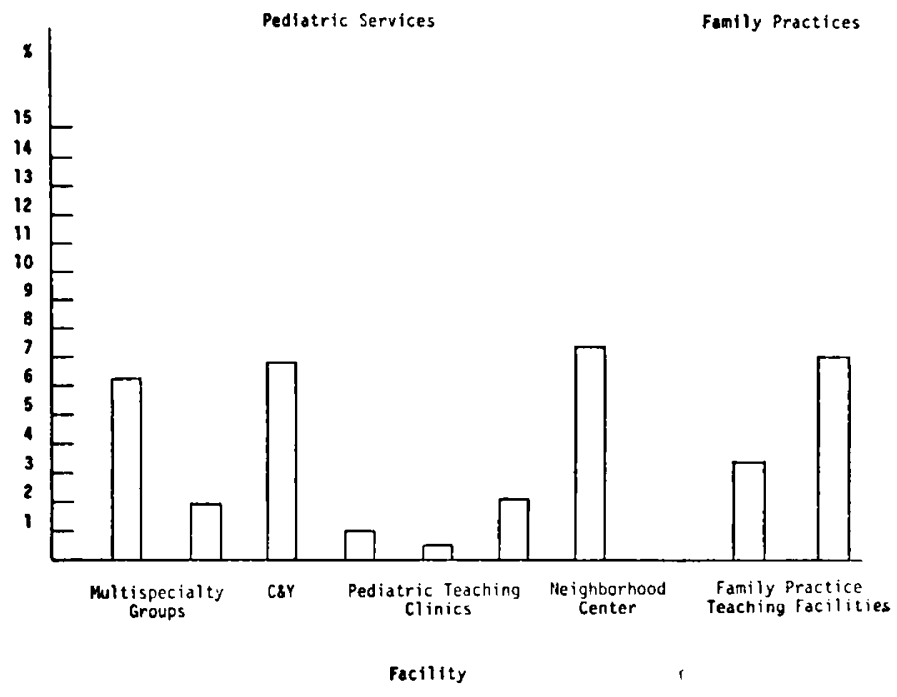

Fig. 1 
Percent of Visits with Pijchoso-jtic Dimonses
Age-Standardiced, 19/7

Pediatric Services

Family Practices

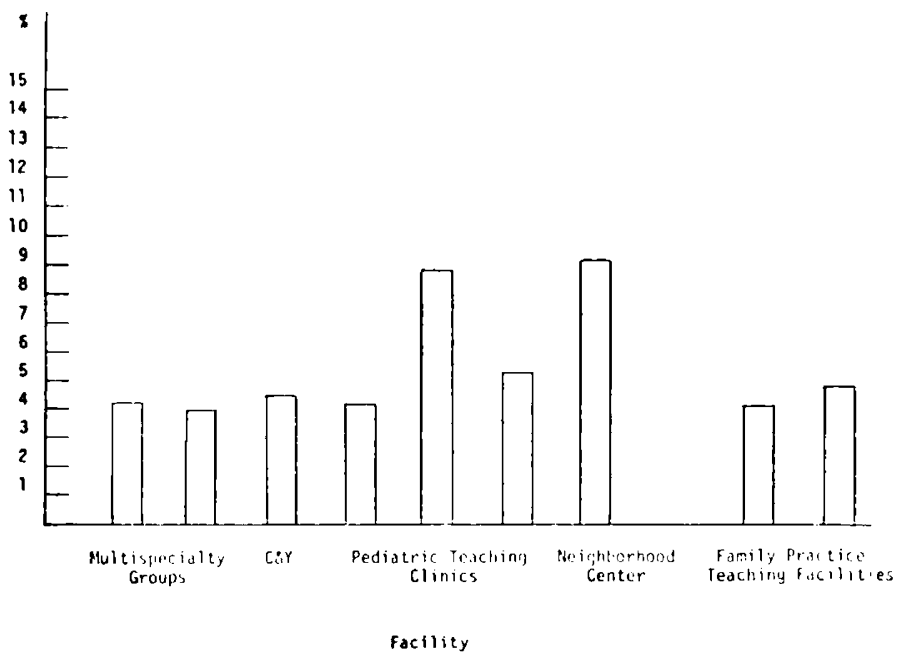

Fig. 2

about the long-term effects of illness (especially with regard to the relationships between the occurrence of one illness and those of others), inadequate knowledge of the impact of illness on child development and functioning in society, and inadequate knowledge of the relationship between illness experience and long-term use of health services.

Although evidence is scanty, a recent review of the literature for evidence regarding the relative constancy and change of physical health in childhood (11) suggested that many childhood conditions generally considered to be acute and self-limited may not be so, but rather that they may be associated with persistent or recurrent dysfunction which is manifested years later. Although the conclusions for specific health conditions must be regarded as tentative because of the relatively limited data, children with problems such as otitis media, mild respiratory problems, behavior problems, and problems such as frequent school absences, use of medication, and restricted activity appear to be at relatively high risk of having these or related conditions later on than other children. Moreover, it appears that children having certain conditions later on in childhood were much more likely to have had antecedents early in life than children without these problemsthat is, conditions such as enuresis, teenage respiratory problems, and urinary tract infection when present later on are found often to have been present earlier. There is also very fragmentary evidence that illnesses, acute and chronic and both together, cluster in the population rather than being distributed randomly (3). Some people have much more than their share of illnesses of all types than others, and some have very little. The average number of illnesses is a statistic that poorly reflects reality.

Use of health services doesn't distribute randomly either. $\mathrm{Na}$ tional statistics inform us about the average number of visits made by children in a year and what proportion of these visits have diagnoses such as upper respiratory infection, otitis media, or any other diagnosis. However, such statistics tell us little about the actual distribution of use of care or illness in children in the population. Figure 3 shows the number of visits (not including those for allergy shots or lab tests) made by children enrolled in an organized comprehensive group practice plan. These particular data are for 12-year-olds, but the same would be found at any age. The mean number of visits made by these children in a year is a bit over three, a statistic that obscures the fact that a third of children made fewer than two visits and $10 \%$ made more than 10 visits. Why this is the case - why some children should only rarely seek care and why some need so much-is poorly understood. It is not a result of a high burden of conditions physicians consider serious and chronic because the proportion of children who are high users is too great for this. More significant even than these one-year findings are data showing that children who are high users in one year are very likely to continue to be high users and vice versa (3). In two facilities separated by 3000 miles and a decade, the proportion of children who show constantly high or constantly low use of services over 6 to 10 years is much greater (13\%) than could be accounted for by chance distribution of high use (4\% of children). The proportion of children who are persistently low users ( 8 to $13 \%$ ) is also higher than the proportion that would be found if use distributed randomly (3\%). Utilization of health services clusters in the population, and patterns of use tend to persist over long periods of time. Why this is so is unexplored.

Research that focuses on particular conditions or particular organ systems and that relies upon data collected in diseaseoriented facilities cannot deal with these realities (summarized in Table 5). To do this, it is necessary to view health problems from a population perspective.

Three examples where the contributions of both basic and clinical research and population or community or epidemiologic research are evident illustrate the usefulness of linkages.

First consider lead poisoning. Basic research, operating on the principle that understanding the internal derangements will lead to reductions in the damage from lead poisoning, is directed at elucidating the mechanisms for the occurrence of encephalopathy, anemia, and other pathologic processes. Clinical research seeks ways of treating and reversing the manifestations of toxicity. As the frequency of plumbism, particularly in certain locales, became increasingly evident and as basic research provided a means of detection and effective therapy, screening tests were devised and used in the community. When these community-based studies suggested that hyperactivity and other behavioral deviations might

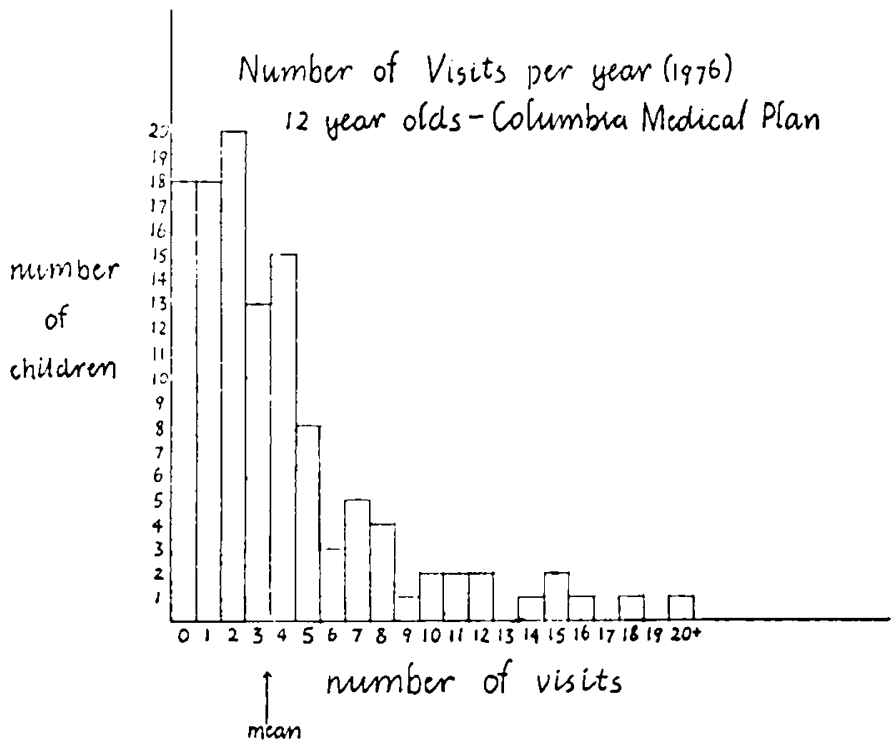

Fig. 3

Table 5. Reasons for diverse approaches to research

1. Inadequate knowledge of the distribution of health problems

2. Inadequate knowledge of how problems initially present

3. Inadequate opportunity to learn the results of care

4. Inadequate recognition of certain types of problems

5. Inadequate knowledge of the interrelationships among health conditions, the use of health services, and the effect of these on subsequent health 
be associated with lead toxicity, the loop from basic to clinical to community research was closed as these observations led to laboratory studies to confirm and explain the observations. The results of screening raised new questions, too, as it became apparent that many children without the classical signs of plumbism were found to have levels of lead as high as in those presenting clinically. A combination of basic, clinical, and population-based research will be required to understand the significance of these new observations and to sort out the relative contributions of biologic and ecologic factors responsible for them.

The second example deals with sudden infant death syndrome (SIDS). Population-based research stimulated interest in this condition because public health statistics showed it to be a major cause of deaths. Once recognized, its high visibility and dramatic nature led relatively rapidly to the support of epidemiologic studies of the distribution and demographic characteristics of infants succumbing to it. Widespread concern also led to clinical studies of the biologic factors associated with these deaths and to basic research into central nervous system and pulmonary pathology. The cycle is now closing as attention is shifting again to community-based research to identify infants and families at high risk from information gained in all three types of research and to test alternative approaches to intervening in high-risk situations. Of great significance for both researchers and practitioners is the likelihood that these interventions clearly will require services in the home rather than in the medical center, probably with the involvement of personnel other than traditional health workers. Thus, for some conditions, even relatively rare ones such as susceptibility to SIDS, much of the research challenge will be in the community.

The third and last example of the relationship between the two types of research deals with psychosocial problems. In contrast to plumbism (about which there is much knowledge) and SIDS (where the accumulation of knowledge is occurring rapidly), extr'mely little is known about psychosocial problems in children at any level of research. Many physicians - pediatricians, too-think these conditions have little relevance for medical research. The reasons for this attitude are varied but can be attributed to beliefs that their cause lies outside the range of things physicians can control, to beliefs that the conditions are transient or merely on the fringes of normal variability, or to simple lack of interest in phenomenon where knowledge (particularly of organ pathophysiology) is so primitive. However, the fact is that communitybased studies are beginning to show that the existence of these conditions can be determined with fair reliability and validity. that they are a great concern to families and the underlying reason for a large number of visits to physicians, and that they are a concomitant (if not the cause) of much pathology that physicians diagnose as organic disease (3). As a result of these populationbased studies, many medical centers and training programs are requesting support to embark upon clinical research on these conditions. Such research focuses upon developing diagnostic tools and on assessing the effects of a variety of types of interventions. Basic research, when it gains momentum, will have to rely initially on population-based research which will define the bounds of the conditions, develop a tentative taxonomy, and elucidate the ecological and social concomitants.

Forging the links between the two types of research is difficult primarily because there has been little experience with mechanisms to facilitate them. Population-based research is usually carried out by faculty located in departments of community medicine or schools of public health who are generally not much in contact with researchers in clinical departments. Other phenomena create difficulties but at the same time highlight even more the need to close the gap between the two types of approaches. First among these factors is great mobility, both of patients and physicians. The ability to compile experiences over long periods of time with a stable population doesn't exist except in a few places nowadays. As a result, there must be much more reliance on shared experiences, such as within organized group settings, and on clinical information systems specifically designed to provide data suitable for clinical or epidemiologic investigations. The second factor inhibiting the linkages between types of research is the increasing fragmentation of care arising as a result of increased entitlement to medical services. Insurance for physician visits, particularly that which pays fee-for-service to any practitioners chosen by the patients, makes it even easier than it is already for patients to visit any number of practitioners, for any number of problems, in any order, without any form of communication among the involved practitioners. The effect on research capability (apart from the inefficiency and high cost of providing the service) is considerable and needs to be addressed. Third, greater survival rates consequent to scientific advances mean that illness experienced in the community is increasing relative to illness experienced in the hospital, and those surviving with a particular illness are now at risk of other illnesses not specifically related to the original illness. The range of outcomes of health care, which has to do with the way people function in their communities with their illness, is widening and becoming increasingly non-disease specific. Different conditions produce impairment of similar functions, and it is increasingly difficult to attribute outcomes to specific medical care interventions for specific conditions. As a result, it is important to be aware of the context in which illness is managed and, particularly, the relationships between one illness and another. Although this increasing variety of possibilities makes research much more complicated, it makes the multilevel approach even more necessary. Perhaps the biggest challenge of all is the emergence of new syndromes not now in the existing lexicon. It is very difficult for practitioners to recognize these phenomena because experience with individual patients is almost always of insufficient frequency to project an awareness of them as separate and distinct new entities. For example, Lyme arthritis was recognized as a new syndrome only when mothers reported their concern about a possible epidemic to the health department. The immensely greater exposure to new environmental and social pathogens consequent to technologic advances creates new risks: the worker exposing his or her children to dusts of unknown and probably mixed composition from workrooms and factories; a multiplicity of pesticide residues in foods; occult radioactivity contained in a variety of products. The manifestations of these events have not even begun to be catalogued, but it is certain that they will be manifested in nonlethal biologic and psychologic derangements more or less symptomatic but certainly not classifiable using standard nomenclature of disease. Only a populationbased approach can point to directions that can be exploited by clinical and basic research.

Difficult as it all seems, there are many things that can be done to forge the links, much more than is being done now. First, it is important to assure that students, housestaff, and fellows continue to be trained to a spirit of inquiry. The decline in interest in research is not only a result of decreases in funding; it siarted a decade ago when many students became disenchanted with what they perceived as a lack of relevance of research to the problems of their world. Their medical center experience did not (and does not) expose them to researchable problems that might capture their interest and their commitment. Research is even more necessary now than it has been in the past, but it must be research with a broadened focus. It is also important that good, young candidates be attracted to it.

A few specific suggestions might be considered. Each trainee. whether in general pediatrics or subspecialty, should keep a record of all patients seen during the training experience. Periodically (perhaps every three months), the trainee and a preceptor should review the complete charts of every patient (or at least a random sample of all patients) seen on inpatient and outpatient services to determine how many visits were made by each patient, to what facility, for what purpose, to ascertain how many patients did not return as advised to, and to ascertain the nature of the results of the treatments recommended. The aims of this exercise are to place the medical care provided in the context of what happens to 
the child (not to the disease) and to build the students' capability to accurately assess medical impact beyond the immediate encounter with the child.

At least once, towards the end of the training program, all traanees should (under faculty guidance) review as a group the entire training experience. What kinds of patients have been seen? How does this compare with the characteristics of the patients in the neighborhood of the hospital and with the general population of children? What types of problems have been diagnosed and managed? What types of approaches have been used for specific problems? What types of outcomes have been achieved? The primary aim of this experience is to provide the trainees with evidence of the variability among them, to explore reasons why their experiences differ, and to consider what implications this has for the way they will practice medicine in the future. Although this will also be important training for the inevitable demand that will be made upon them by mandated peer review, I suggest it not in this context but in the context of fostering an inquisitive mind that can contribute to research regardless of what particular professional position the trainee may ultimately assume.

Those already involved in research need to be constantly aware of the questions requiring linkages between the types of research. Specifically, what are the correlates of disease, biologic and ecologic? What kinds of patients have participated in the research? From what populations are they drawn, and to what extent can research results be generalized to all patients? Can interinstitutional links be forged to surmount the problem of patient selectivity that is characteristic of most medical institutions? How much variability is there among patients regarding the way diseases present, how they are managed, and how they respond? There is far more variability than is commonly assumed, so much so that other ways to describe phenomena in addition to averages, modes. and medians should be developed.

Much more interspecialty collaboration-within pediatrics, with other specialties-is required to deal with manifestations of illness that are common to many or all diseases. Most important in this regard are ideas and proposals about ways to measure outcome of treatment, to access psychosocial attributes and correlates of disease, and to facilitate the recognition of environmental effects on health. An area of high priority concerns the development of methods to describe the health of children. Although most physicians have a clinical sense about how their patients function, there is no way to translate this clinical sense into research data. The dilemma is illustrated by the Health Examination Survey and HANES. They are nationwide surveys of a representative sample of the population, and they consist of an interview and a standardized examination. Such surveys are conducted by the National Center for Health Statistics under Congressional mandate to provide information about the state of health of the population. These surveys are extremely well designed from a methodologic viewpoint. Their data provide much information about things such as hearing levels in the population, the distribution of blood pressures at various ages, and the prevalence of low hemoglobins. These findings can even be translated into specific diagnoses depending upon whether the values fall in the normal range or not. However, what of the situation where there are multiple types of problems, multiple diagnoses, or (as will increasingly be the case) multiple and ill-defined symptom complexes which have no specific diagnosis? The surveys describe much about the state of organ systems but little about what they were intended to describe - the health of people. The problem is primarily a conceptual, not a methodologic one. Advances in this area require the most creative and ingenious researchers.

What population-based research does in combination with clinical and basic pediatric research is to help assure that a wider variety of information bearing on disease causation and management is considered. It aids in specifying the nature of the problem and in defining its context so that the application of diagnostic and therapeutic maneuvers can be applied most efficiently and with the intended effects.

There are many ways to do jigsaw puzzles. Some enthusiasts (but not many I think) pick pieces at random. Others have been observed to choose the most colorful pieces from the box and proceed to build the entirety around the colorful nucleus. Still others find challenge in building upon certain content areas, joining the areas only after each one is complete in its own right. Some of us start with corners and edges, building the framework that defines the range and bounds of the task; the separate areas then are fitted in within the more encompassing framework. The puzzle gets done quickest when the approaches are combinedsome building up, some building down.

So should pediatric research be approached, but the populationbased approach has not been represented in most training programs or in most pediatric research. Academic pediatricians interested in community-based research are much more likely to be appointed heads of departments of community medicine than as heads of pediatric departments, thus depriving the pediatric community of an important component of leadership in these times of great challenge to pediatric training, to research, and to child health care. Health policy in general seems to be made on the basis of political forces by established constituencies rather than by more rational means, but children are not a political force, so the power of research is critical in supporting the development of policy to meet their needs. With the rapidly oncoming economic crisis and the decline in availability of funds for public programs, child health research is easily sacrificed. It is now essential that the inherent links between the types of research be strengthened.

\section{REFERENCES AND NOTES}

1. Dutton. D.: Children's health care: the myth of equal access. Background paper for The Select Panel for the Promotion of Child Health. DHHS (1980)

2. Glantz. S.: Biostatistics. How to detect, correct, and prevent errors in the medical literature. Circulation, 61: 1 (1980).

3. Hinkle, L., and Wolf, H.: The nature of man's adaptation to his total environment and the relation of this to illness. AMA Arch. Intern. Med., 99: 442 (1957).

4. Holtzman, N.: Rare diseases, common problems: recognition and management. Pediatrics, 62: 1056 (1978)

5. Levy, J., Bonanno, R., Schwartz, C., and Sanofsky, P.: Primary care. Patterns of use of pediatric medical facilities. Medical Care 17: 881 (1979).

6. Ley, P. and Spelman, M. S.: Communicating with the patient. (Staples Press, London, England, 1967)

7. National Center for Health Statistics. Health Interview Survey, 1974. Unpublished data (courtesy Mary Grace Kovar) (1980).

8. Sackett, D. L., and Haynes, R. B. (eds): Compliance with therapeutic regimens. (Johns Hopkins University Press. Baltimore. 1976)

9. Sheehan T. J.: The medical literature. Let the researchers beware. Arch. Intern. Med., 140: 472 (1980).

10. Starfield, B., Gross, E., Wood. M.. Pantell, R., Allen, C., Gordon. I. B.. Moffatt P.. Drachman, R., and Katz. H.: Psychosocial and psychosomatic diagnoses in primary care of children. Pediatrics, 66: 159 (1980)

11. Starfield, B., and Pless, I. B.: Constancy and change in physical health. In: $O$ Brim, and J. Kagen: Constancy and change in human development. Harvard University Press, Cambridge, MA (1980)

12. Starfield, B., Simborg, D., Horn, S., and Yourtee, S.: Continuity and coordination in primary care: their achievement and utility. Medical Care, 14: 625 (1976).

13. Starfield, B., van den Berg. B., and Katz. H.: Variations in the utilization of health services by children. Pediatrics, 6.1: 633 (1979)

14. White, K. L.: The ecology of medical care. N. Engl. J. Med., 265: 885 (1961)

15. Williamson, J., Goldschmidt, P., and Jillson. I. A.: Medical practice information demonstration project. Final report. Contract 282-77-0068GS (Office of the Assistant Secretary of Health, Department of Health. Education, and Welfare. 1979).

16. Requests for reprints should be addressed to: Dr. Barbara Starfield. Professor and Division Head. Health Care Organization, and Associate Professor of Pediatrics. The Johns Hopkins University School of Hygiene and Public Health, Division of Health Care Organization, 615 N. Wolfe St., Baltimore, MD 21205 (USA). 